\title{
Lactobacillus sakei S1 Improves Colitis Induced by 2,4,6-Trinitrobenzene Sulfonic Acid by the Inhibition of NF-kB Signaling in Mice
}

\author{
Se-Eun Jang ${ }^{1 *}$ and Sung-Won Min $^{2}$ \\ ${ }^{1}$ Department of Food and Nutrition, Eulji University, Seongnam 13135, Republic of Korea \\ ${ }^{2}$ SG Medical, Seoul, Republic of Korea
}

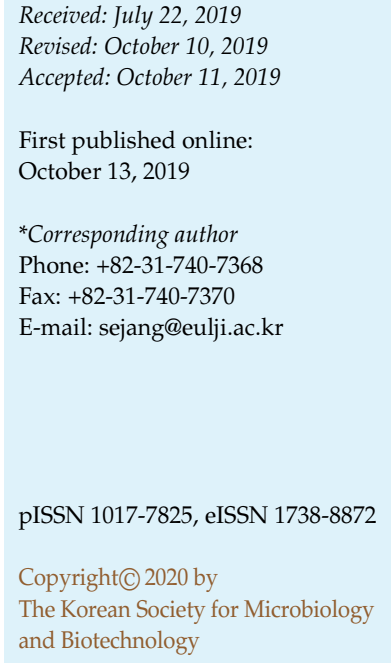

Lactobacillus sakei S1 strongly inhibits the expression of interleukin (IL)-6 and IL-1 $\beta$ in lipopolysaccharide-induced peritoneal macrophages by a mechanism for which lactic acid bacteria from kimchi that inhibit tumor necrosis factor-alpha (TNF- $\alpha$ ) were isolated. Therefore, we further evaluated the protective effect of this strain on the colitis mouse model induced by 2,4,6-trinitrobenzene sulfonic acid (TNBS). TNBS significantly elevated myeloperoxidase (MPO) expression, macroscopic scores, and colon shortening. Oral L. sakei S1 administration resulted in reduction of TNBS-induced loss in body weight, colon shortening, MPO activity, expression of cyclooxygenase (COX)-2, inducible nitric oxide synthase (iNOS) and nuclear factor-kappa B (NF-кB). L. sakei S1 inhibited the expression of inflammatory cytokines IL-1 $\beta$, IL-6 and TNF- $\alpha$, induced by TNBS, but enhanced IL-10 expression. L. sakei S1 showed resistance to artificial digestive juices and adherence to intestinal epithelial Caco-2 cells. Thus, L. sakei S1 may inhibit the NF-кB pathway and be used in functional food to treat colitis.

Keywords: Lactobacillus sakei, probiotics, colitis, 2,4,6-trinitrobenzene sulfonic acid (TNBS), NF-кB

\section{Introduction}

Either progressive or chronic remittent inflammatory conditions are the main characteristics of inflammatory bowel disease (IBD), a group of conditions that include Crohn's disease and ulcerative colitis and cause injury to the colonic mucosa or even the complete gastrointestinal tract, leading to recurrent diarrhea and abdominal pain [1, 2]. Although a clear pathogenesis of IBD has not been established yet, accumulating reports indicate the impaired regulation of immune response of the intestine towards the endotoxins present in intestinal microflora and similar environmental antigens [3]. The human gut microbiota consists of 10 to 100 trillion microorganisms [3]. Among them, more than 1,000 gut bacterial species such as Enterobacteriaceae are closely related to the onset and persistence of ulcerative colitis [4]. Gram-negative bacteria, including Enterobacteriaceae, generate bacterial endotoxins such as lipopolysaccharides (LPS). LPS originating from gut bacteria contribute to the development of metabolic as well as inflammatory disorders [3]. LPS activates NF-кB signaling in macrophages, and this leads to enhanced production of different inflammatory cytokines, such as interleukin (IL)-1 $\beta$, tumor necrosis factor-alpha (TNF- $\alpha$ ), etc. [5]. Inflammation is caused by host immune responses to pathogenic or tissue damage and is mediated by cytokines. TNF- $\alpha$ and IL-1 $\beta$ are the main pro-inflammatory cytokines that cause inflammation [6]. LPS activation of macrophages is the major source of the formation and release of these pro-inflammatory cytokines, which promote the inflammatory response [7]. NF- $\mathrm{B}$ transcription factor is involved in the transcriptional control of the expression of TNF- $\alpha$ and IL-1 $\beta[6,7]$. Thus, the focus of most recent research has been to identify a dietary component that can inhibit the LPS-induced NF- $\kappa B$ signaling pathway to ameliorate IBD [8].

Lactic acid bacteria (LAB) are considered to be beneficial and non-pathogenic microorganisms in the digestive tract [9]; they exhibit anti-obesity effects [10], mitigate infectious and inflammatory diseases [11], and have anti-colic effects [12]. For instance, in mice with dextran sulfate sodium (DSS)induced colitis, Lactobacillus gasseri blocks the biosynthesis 
of inflammatory cytokines [13]. Furthermore, Lactobacillus casei, Bifidobacterium lactis, Lactobacillus plantarum and Bifidobacterium longum also exhibit anti-inflammatory properties in the colitis model [14, 15]. Although several strains of LAB that have anti-colitis effects have been reported, studies on the anti-colitis effects of the new strain of lactic acid bacteria may be helpful in the treatment of socially severe and refractory colitis.

Thus, employing peritoneal macrophages that are stimulated with LPS, the inhibition of TNF- $\alpha$ expression by LAB from kimchi was assessed. Our results revealed the anti-colitis effect of S1, which was identified as L. sakei through genetic analyses.

\section{Materials and Methods}

\section{Materials}

TNBS, sodium thioglycolate, LPS from Escherichia coli O111:B4, and Roswell Park Memorial Institute (RPMI) medium were obtained from Sigma-Aldrich (USA). Radio immunoprecipitation assay (RIPA) buffer was obtained from Abcam (UK). Enzymelinked immunosorbent assay (ELISA) kits for IL-6, IL-1 $\beta$, and TNF- $\alpha$ were purchased from eBioscience (USA). Antibodies against p-p65, p65, cyclooxygenase (COX)-2, inducible NO synthase (iNOS), and $\beta$-actin were procured from Cell Signaling Technology (USA) and Abcam (USA). A Pierce enhanced chemiluminescence (ECL) western blotting substrate was obtained from Thermo Fisher Scientific (USA). The Gram staining kit was obtained from BioMerieux (France).

\section{Isolation and Culture of L. sakei S1}

Forty LAB strains isolated from a Korean traditional fermented food (Chinese cabbage kimchi), were cultured in MRS broth (BD, USA). Identification of the isolated LAB strains was done by $16 \mathrm{~S}$ ribosomal DNA sequencing and Gram staining, by using previously published procedures [3]. An assay was performed to determine the anti-inflammatory activity of LAB in macrophages. LAB were grown in MRS broth under anaerobic conditions at $37^{\circ} \mathrm{C}$. Bacterial cultures were then centrifuged for $20 \mathrm{~min}$ at $5,000 \times g$ and the bacterial pellets were washed with saline. For in vitro assay, the pelleted bacteria were inactivated by being kept at $72^{\circ} \mathrm{C}$ for $30 \mathrm{~min}$, after their suspension in $1 \mathrm{ml}$ of saline (PBS). For in vivo assay, the LAB strain L. sakei S1 was grown in MRS broth until the optical density at $600 \mathrm{~nm}$ was between 1 and 2, followed by centrifugation $(5,000 \times g$ for $20 \mathrm{~min})$, and washing of the pellet with saline. The collected bacterial cells were suspended in $1 \%$ glucose at a density of either $1 \times 10^{8} \mathrm{CFU}$ or $1 \times 10^{9} \mathrm{CFU}$, for oral administration in mice.

\section{Survival Rate of L. sakei S1 on Gastric and Intestinal Juice}

To determine the survival rate in artificial gastric juice and intestinal juice, L. sakei $\mathrm{S} 1$ was first inoculated into artificial gastric juice, cultured at $37^{\circ} \mathrm{C}$ for $3 \mathrm{~h}$ and centrifuged to recover the cells [16]. The recovered bacteria were mixed with the artificial intestinal fluid and incubated for $3 \mathrm{~h}$ at $37^{\circ} \mathrm{C}$. The number of surviving L. sakei S1 was measured by plating on MRS agar. Preparation of artificial gastric juice involved mixing of MRS broth, $\mathrm{pH} 2.5$, adjusted with $1 \mathrm{~N} \mathrm{HCl}$, and pepsin $(1 \mathrm{mg} / \mathrm{ml})$. The artificial intestinal fluid was adjusted to $\mathrm{pH} 6.8$ with Gram broth containing musin $(0.1 \%)$, pancreatin $(0.04 \%)$, bile salt $(0.2 \%)$, trypsin $(0.04 \%)$, and $\mathrm{NaCl}(0.85 \%)$.

The Ability of L. sakei S1 to Attach to Intestinal Epithelial Cells

In order to measure the adherence of isolated LAB strains to intestinal epithelial cells, Caco-2 cells were used. Caco-2 cells obtained from Korean Cell Line Bank (KCLB) were grown in DMEM (Dulbecco's modified Eagle's medium) supplemented with $10 \%$ (v/v) fetal bovine serum (FBS, Sigma-Aldrich), $1 \mathrm{mM}$ sodium pyruvate, $2 \mathrm{mM}$ L-glutamine, $0.1 \mathrm{mg} / \mathrm{ml}$ streptomycin and $100 \mathrm{U} / \mathrm{ml}$ penicillin, in $5 \% \mathrm{CO}_{2}$ incubator at $37^{\circ} \mathrm{C}$. The Caco-2 cells were then harvested and washed with antibiotic-free DMEM and cultured in 6-well culture plates in antibiotic-free DMEM supplemented with FBS, by adjusting the number of Caco- 2 cells to $1.0 \times 10^{5}$ cells $/ \mathrm{ml}$ to form the monolayer. After inoculation, the cells were incubated in $5 \% \mathrm{CO}_{2}$ incubator for $2 \mathrm{~h}$ at $37^{\circ} \mathrm{C}$.

The culture of the L. sakei S1 in the MRS liquid medium at $37^{\circ} \mathrm{C}$ for $24 \mathrm{~h}$ was centrifuged to collect only the bacteria, washed with PBS, pH 7.0, and the number of L. sakei S1 bacterial cells in the DMEM medium was adjusted to $1.0 \times 10^{7} \mathrm{CFU} / \mathrm{ml}$. Caco-2 cells were preincubated with a $L$. sakei S1 suspension and cultured at $37^{\circ} \mathrm{C}$ for $2 \mathrm{~h}$. Non-adherent cells were discarded, and the cells were desensitized with trypsin-EDTA solution to obtain PBS $(\mathrm{pH}$ 7.0) and cultured on MRS agar plates to determine the number of L. sakei S1 [16].

Cells were washed twice with PBS (pH 7.0) and centrifuged $(7,000 \times g, 10 \mathrm{~min})$ at $37^{\circ} \mathrm{C}$ for $24 \mathrm{~h}$ in MRS broth to measure autoaggregation. The cell suspension $(2 \mathrm{ml})$ was vortexed vigorously for approximately $10 \mathrm{~s}$ and incubated at $37^{\circ} \mathrm{C}$ for $2 \mathrm{~h}$. The supernatant $(1 \mathrm{ml})$ was collected, and the absorbance at $600 \mathrm{~nm}$ was measured. The self-cohesive force (\%) was determined by substituting the equation [ $(1-$ absorbance after incubation for $2 \mathrm{~h}$ /absorbance before incubation) $\times 100$ ] [17] .

\section{Animals}

Five-week-old male ICR mice (weighing 26-28 g) were supplied from Orient Bio Inc. (Korea). Mice were housed and maintained at $20 \pm 5^{\circ} \mathrm{C}$ and $12 \mathrm{~h}$ dark/light cycles, at six mice per cage, with full access to a diet of standard laboratory chow and water. All animal experiments were approved by the Committee for the Care and Use of Laboratory Animals at Eulji University and performed in accordance with the guidelines of the Eulji University Institutional Animals Care and Usage Committee (IACUC) (Approval No. EUIACUC 18-06). 


\section{Preparation of Macrophages}

Male ICR mice were given thioglycolate injections ( $2 \mathrm{ml}$ of $4 \%$ solution (w/v); intraperitoneally) and were sacrificed 4 days after the injection [18]. RPMI $1640(5 \mathrm{ml})$ was used to flush the peritoneal cavity to collect the peritoneal fluid, which was centrifuged for $5 \mathrm{~min}$ at $300 \times g$. Approximately $1 \times 10^{6}$ cells were seeded in culture plates, incubated in RPMI 1640 containing 10\% FBS and $1 \%$ antibiotic-antimycotic at $37^{\circ} \mathrm{C}$ overnight, and washed twice. The cells attached to the plates were employed as macrophages. To determine the levels of pro-inflammatory cytokines, LPS $(100 \mathrm{ng} / \mathrm{ml})$ was added to the cultured peritoneal macrophages $\left(1 \times 10^{6}\right.$ cells/well), either with or without a varying number of $L$. sakei S1 $\left(1 \times 10^{3}, 1 \times 10^{4}\right.$, or $1 \times 10^{5} \mathrm{CFU} /$ well $)$ for $24 \mathrm{~h}$.

\section{Induction and Evaluation of Colitis in Mice}

For in vivo experiment, mice were separated into 5 experimental groups; (1) a vehicle only treated normal control group; (2) a TNBS only given control group; $(3,4)$ two separate groups treated with TNBS and L. sakei S1 at $1 \times 10^{8}$ or $1 \times 10^{9} \mathrm{CFU} /$ mouse, respectively; (5) a positive control group of mice treated with sulfasalazine $(50 \mathrm{mg} / \mathrm{kg})$ and TNBS.

Induction of colitis was done by the intrarectal injection of a $2.5 \%(\mathrm{w} / \mathrm{v})$ TNBS solution $(100 \mu \mathrm{l})$ in $50 \%(\mathrm{v} / \mathrm{v})$ ethanol into the colon of the mice [18]. For intrarectal injection of TNBS solution, the needle was introduced about $3.5-4 \mathrm{~cm}$ proximal to the anus area. In order to achieve even distribution of TNBS solution throughout colon, mice were held vertically for $30 \mathrm{sec}$ following TNBS injection. L. sakei S1 $\left(1 \times 10^{8} \mathrm{CFU} /\right.$ mouse or $1 \times 10^{9} \mathrm{CFU} /$ mouse $)$ or sulfasalazine $(50 \mathrm{mg} / \mathrm{kg}$ ) was orally administered once a day for 3 days after TNBS treatment. Mice were sacrificed $18 \mathrm{~h}$ after the final administration of $L$. sakei S1 or sulfasalazine. The colon was removed rapidly, and washed gently with saline after opening it longitudinally. Assessment of colitis by macroscopic score was as follows: 0 , absence of ulcer or inflammation; 1 , no ulcers or local hyperemia; 2 , ulceration in the absence of hyperemia; 3 , one site only of inflammation and ulceration; 4 , two or more sites of inflammation and ulceration; 5, ulceration spreading $>2 \mathrm{~cm}$ ( $\left(\right.$ im et al., 2016). Colonic tissues were stored at $-80^{\circ} \mathrm{C}$ until experiments were completed, and some tissues were stored in $4 \%$ PFA for tissue staining.

\section{Myeloperoxidase (MPO) Activity Assay}

Activity of MPO was assayed according to previously described procedures by Lim et al. [18]. The colon tissues were homogenized in $10 \mathrm{mM}$ phosphate buffer ( $\mathrm{pH} 7.0$ ) containing $0.5 \%$ hexadecyltrimethylammonium bromide $(\mathrm{HTAB})$ and were centrifuged for $20 \mathrm{~min}$ at $4^{\circ} \mathrm{C}$ at $20,000 \times g$. MPO activity was measured in the supernatants $(50 \mu \mathrm{l})$. An aliquot $(50 \mu \mathrm{l})$ of the supernatant containing crude MPO was incubated at $37^{\circ} \mathrm{C}$ in an assay mixture with $0.1 \mathrm{mM} \mathrm{H}_{2} \mathrm{O}_{2}$ and $1.6 \mathrm{mM}$ tetramethyl benzidine (TMB), followed by the measurement of optical density at $650 \mathrm{~nm}$. One unit of the MPO activity is defined as the amount of enzyme required to degrade $1 \mu \mathrm{mol}$ peroxide $/ \mathrm{ml}$, and is shown as unit/mg protein [18].

\section{Histopathological Study}

To examine mucosal defects, hemorrhage, or inflammatory lesions, the isolated colons were fixed in 10\%-buffered formalin, and embedded in blocks of paraffin. These colon-embedded paraffin blocks were cut into $5-\mu \mathrm{m}$ thick sections, which were stained with hematoxylin-eosin, followed by examination using light microscopy.

\section{Immunoblot Analysis and ELISA}

For the immunoblot analysis, the colon tissues were lysed with RIPA lysis buffer and centrifuged at $15,000 \times g$ at $4^{\circ} \mathrm{C}$ for $20 \mathrm{~min}$. After extracting the colon lysates using SDS sample buffer, proteins were separated by $10 \%$ sodium dodecyl sulfate-polyacrylamide gel electrophoresis, and then electro-transferred onto nitrocellulose membrane. The membrane was blocked with $5 \%$ non-fat dried milk proteins, and probed with iNOS, COX-2, p65, p-p65, or $\beta$-actin antibodies. Each of these proteins was detected after incubations with a corresponding secondary antibody conjugated with horseradish peroxidase (HRP) for $1 \mathrm{~h}$. Enhanced chemiluminescence (ECL) reagent was used to visualize the protein bands [18].

In the cytokine assay, the supernatants from the lysates of colon homogenates and peritoneal macrophages were added into 96well ELISA plates. The expression levels of TNF- $\alpha$, IL-1 $\beta$, IL- 6 , and IL-10 were determined using ELISA kits for each according to the recommended protocol [18].

\section{Statistical Analysis}

All the results are shown as mean \pm standard deviation (SD). Analysis of statistical significance was done using one-way analysis of variance (ANOVA) followed by post hoc analysis using Dunnett's comparison tests. Differences at $p<0.05$ were considered significant statistically.

\section{Results and Discussion}

\section{Sakei S1 Inhibits the Pro-Inflammatory Cytokine Level in LPS-Stimulated Peritoneal Macrophages}

When the TNF- $\alpha$ inhibitory effect of 40 LAB strains (heattreated) isolated from kimchi was measured in peritoneal macrophages stimulated with LPS, we discovered that S1 profoundly inhibited the synthesis of TNF- $\alpha$. S1 also inhibited the elevated expression of IL- $1 \beta$ and IL- 6 due to LPS induction (Fig. 1). These data are in agreement with the findings of Kwon et al., who showed that in peritoneal macrophages, blockade of IL-1 $\beta$ caused IL-6 inhibition through the interactions of IL-1 $\beta$ and IL-6 [19]. The expression of TNF- $\alpha$, IL-1 $\beta$, and IL-6 in S1-treated group $\left(1 \times 10^{5} \mathrm{CFU} / \mathrm{ml}\right)$ was significantly decreased by $59.7 \%$, $54.5 \%$, and $60 \%$, respectively, in comparison with the LPS alone-treated control group. S1, which was selected as the most active strain, was identified as L. sakei through Gram staining and $16 \mathrm{~S}$ ribosomal DNA sequencing. 

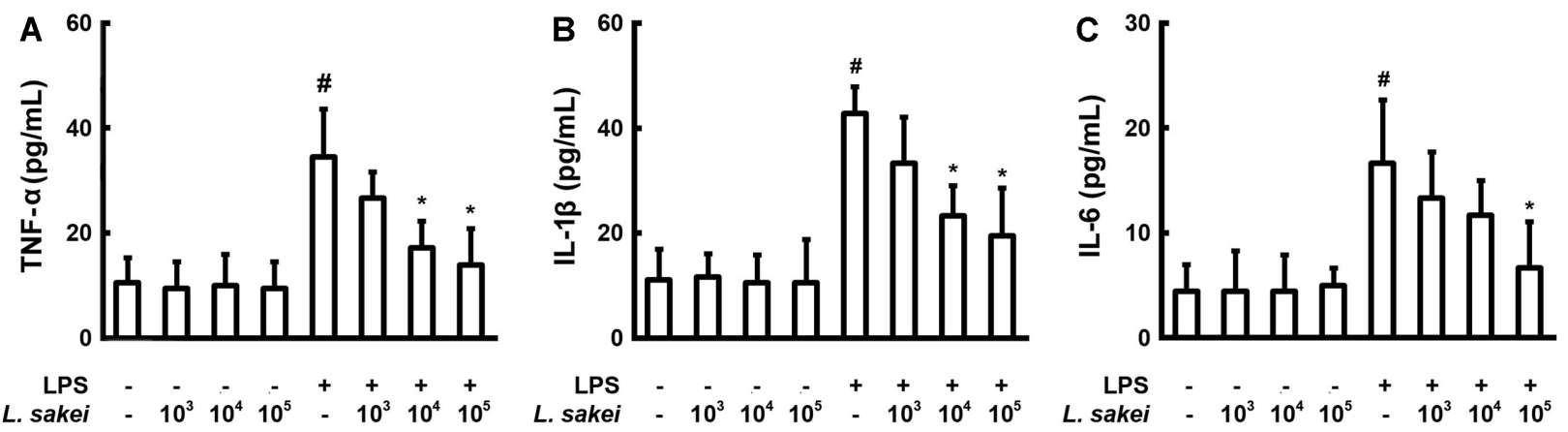

Fig. 1. Effect of Lactobacillus sakei S1 on the expression of TNF- $\alpha(\mathbf{A}), \mathrm{IL}-1 \beta(\mathbf{B})$, and IL-6 (C) in peritoneal macrophages, activated by LPS. $100 \mathrm{ng} / \mathrm{ml}$ LPS was used to treat the peritoneal macrophages $\left(1 \times 10^{6}\right.$ cells/well $)$ in the presence or absence of L. sakei S1 $\left(1 \times 10^{3}, 1 \times 10^{4}\right.$, and $1 \times 10^{5} \mathrm{CFU} /$ well $)$ for $20 \mathrm{~h}$.

ELISA was used to determine the levels of IL-1 $\beta$, IL-6, and TNF- $\alpha$ in the culture supernatants. L. sakei S1 inactivated in boiling water bath for 30 min was employed. Enzyme activity values are represented as mean $\pm \operatorname{SD}(n=3)$. "Significantly different in comparison with the normal control $(p<0.05)$ * *Significantly different in comparison with the LPS alone-treated group $(p<0.05)$.

\section{Resistance to Artificial Digestive Juices of L. Sakei S1 and} Adhesion to Intestinal Epithelial Caco-2 Cells

In order to evaluate the possibility of using L. sakei S1 as a functional food material for humans, its resistance to artificial digestive juice and adhesion to Caco-2 cells were confirmed. Table 1 shows the viable counts of L. sakei S1, the strain isolated from kimchi after culturing in artificial digestion solution. L. sakei S1 was found to be resistant to strong acid at $\mathrm{pH} 2.5$, with pepsin added at more than $3.0 \pm$ $1.5 \times 10^{7} \mathrm{CFU} / \mathrm{ml}$. In order to confirm the resistance to artificial intestinal fluid, viable cell counts were checked, and more than $10^{8} \mathrm{CFU} / \mathrm{ml}$ of live cells were detected, so the resistance to artificial intestinal fluids was significantly high. These results are similar to those of the LAB used in currently available probiotic products [16]. Many LAB are known to exhibit a strong survival rate in the intestinal environment because of their high resistance to bile, which has been reported to be due to bile-enzyme [20].

On the other hand, the self-cohesive force indicates the clusterability between the same bacterial cells, and the selfcohesive force of probiotic strains correlates with the ability of the strain to adhere to intestinal epithelial cells. It is known that bacteria can easily form colonies in the intestinal tract and are resistant to this environment [21].
After incubation for $24 \mathrm{~h}$, L. sakei S1 showed very high self-cohesion. In general, probiotic strains exhibit higher self-cohesion than that of pathogens, and strains with high adherence to hydrocarbons are known to have high selfcohesion [21]. In addition, some LAB have the ability to coagulate with the same strain or different species, thereby enhancing the adhesion to the epithelial cell mucosa. LAB are also able to bind with extracellular matrix molecules such as epithelial cells, mucosal layers, or mucosal components such as collagen, fibronectin, and vitronectin [22].

Adherence and proliferation of LAB on the surface of intestinal epithelial cells are important requirements for a probiotic strain. It is known that strains with strong adherence excel in metabolic and immunomodulating effects, induce immunological activity effectively, stabilize the intestinal mucosal barrier, and inhibit adherence of pathogenic bacteria to epithelial cells [22]. The resistance of L. sakei S1 to artificial digestive juice as well as its excellent adhesion to intestinal epithelial cells make this strain a promising material for functional foods.

\section{L. sakei S1 Ameliorates TNBS-Induced Colitis in Mice}

Anti-colitic effects of L. sakei S1 were evaluated using a TNBS-induced colitis mouse model. The mechanisms of

Table 1. Resistance to artificial digestive juices of Lactobacillus sakei S1 and adhesion to intestinal epithelial Caco-2 cells.

\begin{tabular}{cccc}
\hline & & Viable cell counts (CFU/ml) & Auto aggregation (\%) \\
\cline { 2 - 4 } & Gastric juice & Intestinal juice & Adhesion \\
\hline L. sakei S1 & $3.0 \pm 1.5 \times 10^{7}$ & $1.6 \pm 0.5 \times 10^{8}$ & $4.0 \pm 1.1 \times 10^{5}$ \\
\hline
\end{tabular}

Numbers of L. sakei S1 were counted by plating serial dilutions (in diluted anaerobic broth, $\mathrm{pH}$ 7.2) on MRS and BL agars followed by anaerobic incubation at $37^{\circ} \mathrm{C}$ for $48 \mathrm{~h}$. All values are mean $\pm \mathrm{SD}(n=6)$. 
A

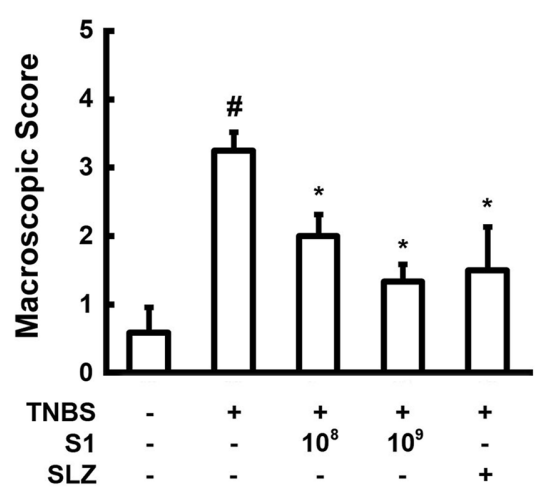

C

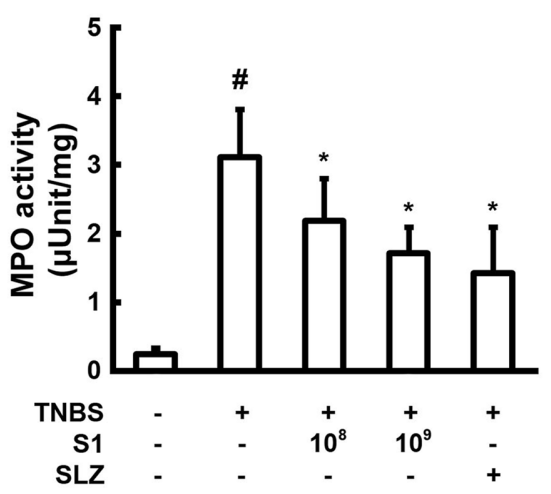

B

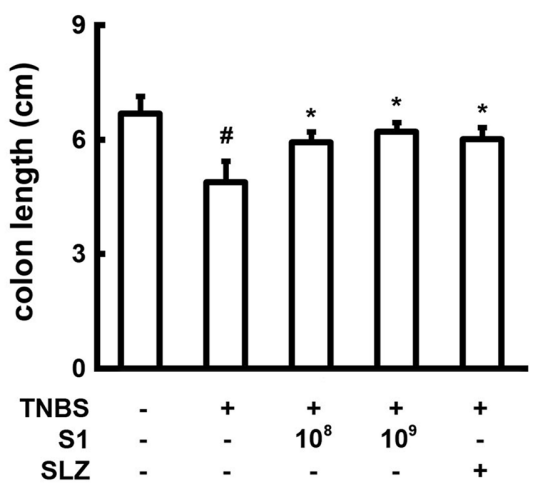

D

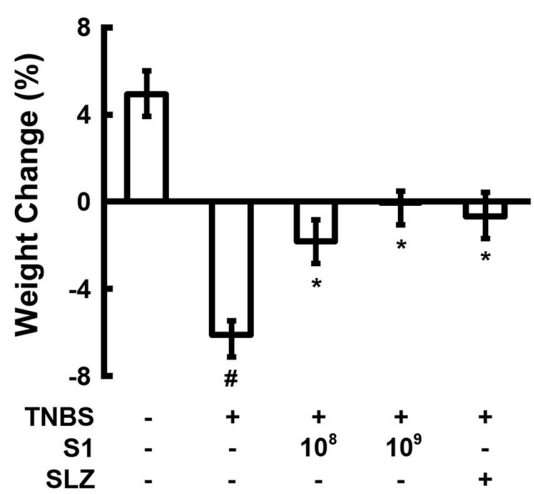

E

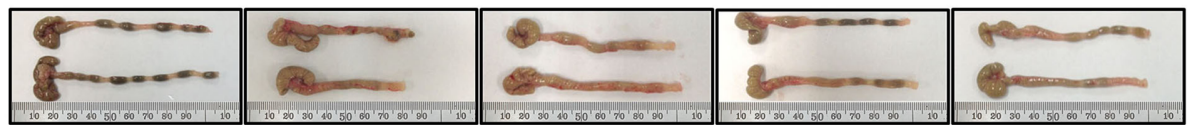

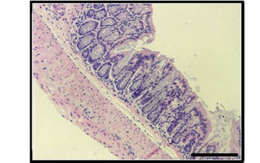

TNBS

S1

SLZ

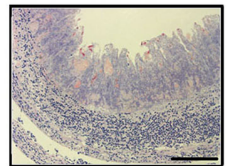

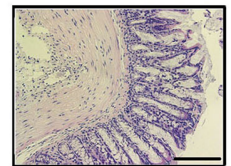

$\stackrel{+}{10^{8}}$

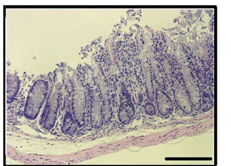

$\stackrel{+}{10^{9}}$

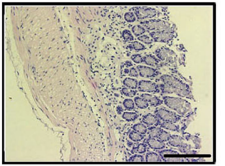

Fig. 2. Effect of Lactobacillus sakei S1 on macroscopic disease (A), colon length (B), colonic MPO activity (C), body weight (D), and colon histology (E) in TNBS-induced colitis in mice.

TNBS, except in the normal control group, was intrarectally administered to mice and test agents [saline, L. sakei S1 $\left(1 \times 10^{8}\right.$ or $1 \times 10^{9} \mathrm{CFU} /$ mouse), or sulfasalazine (SLZ; $50 \mathrm{mg} / \mathrm{kg}$ )] were orally administered for 3 days. The mice were anesthetized and sacrificed $20 \mathrm{~h}$ after the final treatment with LAB. All values are represented as mean $\pm \mathrm{SD}(n=6)$. " Significantly different compared to the normal control group ( $p<0.05)$.

*Significantly different compared to the group treated with TNBS alone $(p<0.05)$. Scale bars: $50 \mu \mathrm{m}$.

IBD pathogenesis in animals is generally studied using the experimental model of TNBS-induced colitis [23]. Inasmuch as the TNBS-induced colitis shows positive response to different currently available IBD therapies, such as antiTNF alpha antibody treatment and sulfasalazine, this is a highly useful model to examine the efficacy of different novel anti-inflammatory therapies [24, 25].
Mice, following the intrathecal administration of TNBS, had loss of body weight, profound colonic inflammation and colon shortening (Fig. 2). The histological assessment of TNBS treated mouse colons revealed a high degree of bowel edema, intense infiltration of the mucosal superficial layers, in association with the destruction of the colonic epithelial cells. Administration of L. sakei S1 hindered 
A

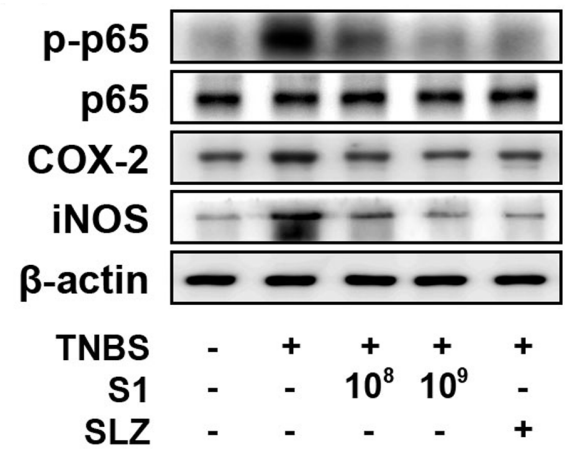

B

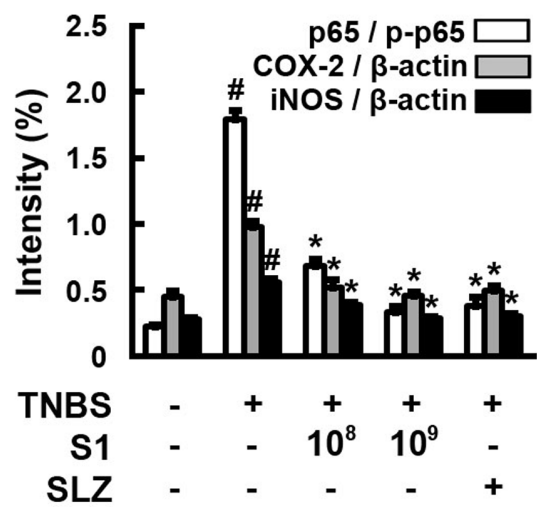

Fig. 3. Effect of Lactobacillus sakei S1 on NF-кB in TNBSinduced colitis in mice.

TNBS, except in the normal control group, was intrarectally administered to mice and test agents [saline, L. sakei S1 $\left(1 \times 10^{8}\right.$ or $1 \times$ $10^{9} \mathrm{CFU} /$ mouse), or sulfasalazine (SLZ; $50 \mathrm{mg} / \mathrm{kg}$ )] were orally administered for 3 days. The mice were anesthetized and sacrificed $20 \mathrm{~h}$ after the final administration of L. sakei S1. The protein levels were determined by immunoblotting.

weight loss, colon shortening, inflammation, and thickening of colons. L. sakei S1 also decreased bowel edema and inhibited infiltration of immune cells and destruction of epithelial cells in histological examination.

In addition, L. sakei S1 inhibited the TNBS-induced activity of MPO, a highly expressed enzyme in the granules that catalyzes the formation of highly reactive oxygen species (ROS), which are considered to be the biomarkers for oxidative damage. TNBS also promoted COX-2 and iNOS expression and activation of NF-kB (Fig. 3). Enhanced production of COX-2 and iNOS has been described in IBD and also in the animal models of intestinal inflammation [19]. L. sakei $\mathrm{S1}$ inhibited the induction of p65 phosphorylation by TNBS and decreased the TNBS-induced expression of iNOS and COX-2. The inhibitory effect of L. sakei S1 $\left(1 \times 10^{9}\right.$ $\mathrm{CFU})$ was more than that of sulfasalazine $(50 \mathrm{mg} / \mathrm{kg})$.
When pro-inflammatory cytokine levels were measured in colon lysate, TNBS increased cytokine levels, including TNF- $\alpha$, IL-1 $\beta$, and IL- 6 but decreased the expression of IL10 (Fig. 4). Oral administration of L. sakei S1 reduced the expression of TNF- $\alpha$, IL-1 $\beta$, and IL-6. However, L. sakei S1 strongly increased the expression of IL-10. The cytokine IL10 has potent anti-inflammatory properties and thereby curtails immune responses of the host to pathogens. Thus, IL-10 alleviates injury to the host and at the same time maintains normal tissue homeostasis [26]. Dysregulation of IL-10 function and synthesis is accompanied by aggravated immunopathological responses towards infection and also elevated risk for IBD and many such inflammatory diseases [26]. L. sakei $\mathrm{S} 1$ treatment recovered $33.2 \%$ of the IL-10 expression compared to the negative control, whereas it inhibited TNF- $\alpha$, IL-1 $\beta$, and IL-6 cytokine expression by $35 \%, 41 \%$, and $23.6 \%$, respectively.

Many normal cellular functions such as proliferation, adhesion and inflammatory responses are controlled by the ubiquitous transcription factor, NF- $\mathrm{kB}$ [6]. NF- $\mathrm{\kappa B}$, which is normally present as an inactive heterodimer of p50 and p65 (RelA) subunits in the cytoplasm, translocates to the nucleus following stimulation by endotoxins such as LPS. The activated NF-kB (pp65) in the nucleus, binds its specific sites on DNA, and triggers the transcriptional activation for the expression of TNF- $\alpha$ and IL-1 $\beta$ [27]. These pro-inflammatory cytokines further activate NF- $\mathrm{kB}$ through a positive feedback mechanism [28]. Thus, it is necessary to block these inflammatory cytokines as much as possible to inhibit NF- $\mathrm{KB}$ signaling in IBD. For these reasons, anti-TNF- $\alpha$ antibodies have been used clinically. However, it is very important to develop safe therapeutic LAB formulations, because the reactivity of drugs used in clinical practice is low, and side effect problems remain [29]. L. sakei S1 suppressed inflammatory cytokines while inhibiting NF- $\mathrm{KB}$, and it may be developed as a functional LAB for colitis.

Although inflammation is a protective response of the host immunity, abnormal inflammatory responses can cause host tissue damage [30]. IBD is a severe inflammatory disease of the intestine in humans, and it is essential to clearly understand the pathogenesis of IBD, because its incidence is increasing steadily worldwide [30]. The pathogenesis of IBD is considered to be mediated through a complex intestinal mucosal immune response towards the resident intestinal microflora [31]. This study showed that endotoxins such as LPS produced by gut microbiota stimulated the NF-кB pathway, which might be a possible cause of IBD. L. sakei showed the possibility of ameliorating 

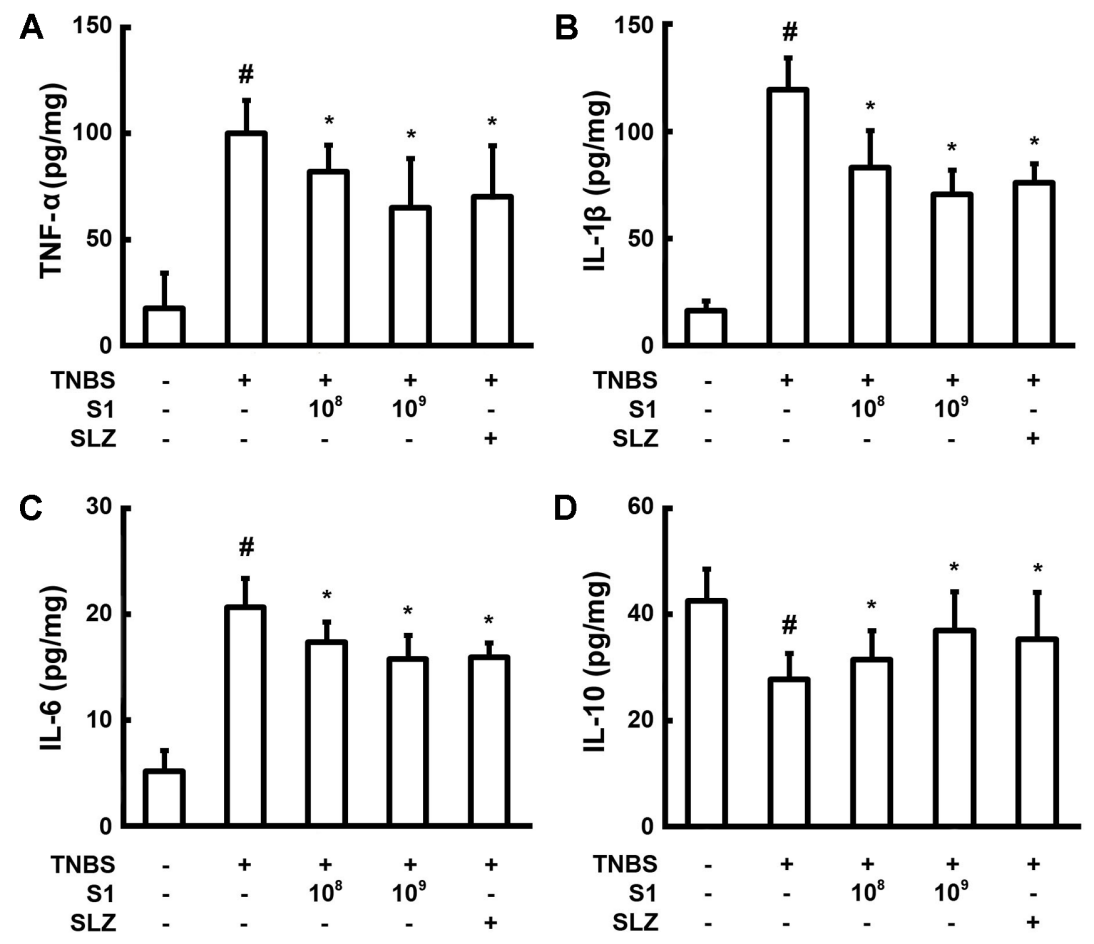

Fig. 4. The effect of Lactobacillus sakei S1 on the synthesis of pro-inflammatory cytokines TNF- $\alpha$ (A), IL-1 $\beta$ (B), and IL-6 (C), and anti-inflammatory cytokine IL-10 (D) in TNBS-induced colitis in mice.

TNBS, except in the normal control group, was intrarectally administered to mice and test agents [saline, L. sakei S1 $\left(1 \times 10^{8}\right.$ or $\left.1 \times 10^{9} \mathrm{CFU} / \mathrm{mouse}\right)$, or sulfasalazine (SLZ; $50 \mathrm{mg} / \mathrm{kg}$ )] were orally administered for 3 days. The mice were anesthetized and sacrificed $20 \mathrm{~h}$ after the final administration of $L$. sakei S1. The cytokine levels in colon were measured by using ELISA. All values are represented as mean \pm SD $(n=6)$. " Significantly different compared to the normal control group $(p<0.05)$. *Significantly different compared to the group treated with TNBS alone $(p<0.05)$.

colitis by inhibiting the NF-кB pathway.

Collectively, the above findings suggest that L. sakei S1 likely prevents colitis by antagonizing the NF- $\mathrm{B}$ pathway and thereby inhibiting the formation of TNF- $\alpha$, IL-1 $\beta$, and IL-6, the major pro-inflammatory cytokines. In addition, $L$. sakei S1, a plant-derived LAB isolated from kimchi, a representative fermented food in Korea, may be a material for functional food applications against IBD.

\section{Acknowledgements}

This work was supported by the National Research Foundation of Korea (NRF) grant funded by the Korea government (MSIP; Ministry of Science, ICT \& Future Planning) (No. NRF-2017R1C1B5077047).

\section{Conflict of Interest}

The authors have no financial conflicts of interest to declare.

\section{References}

1. Neuman MG, Nanau RM. 2012. Inflammatory bowel disease: role of diet, microbiota, life style. Trans. Res. 160: 29-44.

2. Shanahan F. 2002. Gut flora in gastrointestinal disease. Eur. J. Surg. Suppl. 587: 47-52.

3. Jang SE, Han MJ, Kim SY, Kim DH. 2014. Lactobacillus plantarum CLP-0611 ameliorates colitis in mice by polarizing M1 to M2-like macrophages. Int. Immunopharmacol. 21: 186192.

4. Chandran P, Satthaporn S, Robins A, Eremin O. 2003. Inflammatory bowel disease: dysfunction of GALT and gut bacterial flora (I). Surgeon 1: 63-75.

5. Aderem A, Ulevitch RJ. 2000. Toll-like receptors in the induction of the innate immune response. Nature 406: 782787.

6. Min SW, Ryu SN, Kim DH. 2010. Anti-inflammatory effects of black rice, cyanidin-3-O- $\beta$-D-glycoside, and its metabolites, cyanidin and protocatechuic acid. Int. Immunopharmacol. 10: 959-966. 
7. Hutchison S, Choo-Kang BS, Bundick RV, Leishman AJ, Brewer JM, McInnes IB, et al. 2008. Tumour necrosis factoralpha blockade suppresses murine allergic airways inflammation. Clin. Exp. Immunol. 151: 114-122

8. Lee IA, Park YJ, Joh EH, Kim DH. 2011. Soyasaponin Ab ameliorates colitis by inhibiting the binding of lipopolysaccharide (LPS) to Toll-like receptor (TLR) 4 on macrophages. J. Agric. Food Chem. 59: 13165-13172.

9. Collins MP, Gibson GR. 1999. Probiotics, prebiotics, and synbiotics: approaches for modulating the microbial ecology of the gut. Am. J. Clin. Nutr. 69: 1052S-1057S.

10. Aggarwal J, Swami G, Kumar M. 2013. Probiotics and their effects on metabolic diseases: an update. J. Clin. Diagn. Res. 7: 173-177.

11. Romeo J, Nova E, Wärnberg J, Gómez-Martínez S, Díaz Ligia LE, Marcos A. 2010. Immunomodulatory effect of fibres, probiotics and synbiotics in different life-stages. Nutr. Hosp. 25: 341-349.

12. Peran L, Sierra S, Comalada M, Lara-Villoslada F, Bailon E, Nieto A, et al. (2007). A comparative study of the preventative effects exerted by two probiotics, Lactobacillus reuteri and Lactobacillus fermentum, in the trinitrobenzenesulfonic acid model of rat colitis. Br. J. Nutr. 97: 96-103.

13. Okada $Y$, Tsuzuki $Y$, Takeshi T, Furuhashi H, Higashiyama M, Watanabe C, et al. 2018. Novel probiotics isolated from a Japanese traditional fermented food, Funazushi, attenuates DSS-induced colitis by increasing the induction of high integrin $\alpha \mathrm{v} / \beta 8$-expressing dendritic cells. J. Gastroenterol. 53: 407-418.

14. Bellavia M, Rappa F, Lo Bello M, Brecchia G, Tomasello G, Leone A, et al. 2014. Lactobacillus casei and Bifidobacterium lactis supplementation reduces tissue damage of intestinal mucosa and liver after 2,4,6-trinitrobenzenesulfonic acid treatment in mice. J. Biol. Regul. Homeost. Agents. 28: 251-261.

15. Jang SE, Jeong JJ, Kim JK, Han MJ, Kim DH. 2018. Simultaneous amelioratation of colitis and liver injury in mice by Bifidobacterium longum LC67 and Lactobacillus plantarum LC27. Sci. Rep. 8: 7500.

16. Jang SE, Hyun YJ, Oh YJ, Choi KB, Kim T, Yeo IH, et al. 2011. Adhesion activity of Lactobacillus plantarum PM 008 isolated from Kimchi on the intestine of mice. J. Bacteriol. Virol. 41: 83-90.

17. Kos B, Suskovic J, Vukovic S, Simpraga M, Frece J, Matosic S. 2003. Adhesion and aggregation ability of probiotic strain Lactobacillus acidophilus M92. J. Appl. Microbiol. 94: 981-987.

18. Lim SM, Jeong JJ, Jang SE, Han MJ, Kim DH. 2016. A mixture of the probiotic strains Bifidobacterium longum $\mathrm{CH} 57$ and Lactobacillus brevis $\mathrm{CH} 23$ ameliorates colitis in mice by inhibiting macrophage activation and restoring the Th17/ Treg balance. J. Funct. Foods. 27: 295-309.
19. Kwon KH, Murakami A, Hayashi R, Ohigashi H. 2005. Interleukin-1beta targets interleukin-6 in progressing dextran sulfate sodium-induced experimental colitis. Biochem. Biophys. Res. Commun. 337: 647-654.

20. Ljungh A, Wadstrom T. 2006. Lactic acid bacteria as probiotics. Curr. Issues Intestinal Microbiol. 7: 73-90.

21. Lee KW, Park JY, Sa HD, Jeong JH, Jin DE, Heo HJ, et al. 2014. Probiotic properties of Pediococcus strains isolated from Jeotgals, salted and fermented Korean sea-food. Ananerobe 28: 199-206.

22. Saarela M, Mogensen G, Fonden R, Matto J, MattilaSandholm T. 2000. Probiotic bacteria: safety, functional and technological properties. J. Biotechnol. 84: 197-215.

23. Fiorucci S, Mencarelli A, Palazzetti B, Sprague AG, Distrutti E, Morelli A, et al. 2002. Importance of innate immunity and collagen binding integrin alpha1beta1 in TNBS-induced colitis. Immunity 17: 769-780.

24. Neurath MF, Fuss I, Pasparakis M, Alexopoulou L, Haralambous S, Meyer zum Büschenfelde, KH, et al. 1997. Predominant pathogenic role of tumor necrosis factor in experimental colitis in mice. Eur. J. Immunol. 27: 1743-1750.

25. Fiorucci S, Mencarelli A, Palazzetti B, Distrutti E, Vergnolle N, Hollenberg MD, et al. 2001. Proteinase-activated receptor (PAR)-2 is an anti-inflammatory signal for colonic lamina propria lymphocytes in a mouse model of colitis. Proc. Natl. Acad. Sci. USA 98: 13936-13941.

26. Iyer SS, Cheng G. 2012. Role of interleukin 10 transcriptional regulation in inflammation and autoimmune disease. Crit. Rev. Immunol. 32: 23-63.

27. Barens PJ, Karin M. 1997. Nuclear factor-kappaB: a pivotal transcription factor in chronic inflammatory diseases. $N$. Engl. J. Med. 336: 1066-1071.

28. Collins T, Read MA, Neish AS, Whitley MZ, Thanos D, Maniatis T. 1995. Transcriptional regulation of endothelial cell adhesion molecules: NF- $\mathrm{BB}$ and cytokine inducible enhancers. FASEB. J. 9: 899-909.

29. Yu YR, Rodriguez JR. 2017. Clinical presentation of Crohn's, ulcerative colitis, and indeterminate colitis: symptoms, extraintestinal manifestations, and disease phenotypes. Semin. Pediatr. Surg. 26: 349-355.

30. Chami B, Martin NJJ, Dennis JM, Witting PK. 2018. Myeloperoxidase in the inflamed colon: a novel target for treating inflammatory bowel disease. Arch. Biochem. Biophys. 645: 61-71.

31. Jang SE, Hyam SR, Jeong JJ, Han MJ, Kim DH. 2013. PentaO-galloyl- $\beta$-D-glucose ameliorates inflammation by inhibiting MyD88/NF-кB and MyD88/MAPK signalling pathways. Br. J. Pharmacol. 170: 1078-1091. 